\title{
The Neutral role of Interpreters under the Cognitive Model of Interpreting
}

\author{
Weitian Deng \\ Department of Linguistics, Vrije Universiteit Brussel, Belgium \\ Department of English, Tianjin University of Technology, China \\ Email: dengweitian1214@gmail.com
}

Keywords: interpreting; cognitive model; meaning construction; neutrality

\begin{abstract}
Interpreting model is of great significance for interpreters in terms of theory and practice alike. Compared with other models, the cognitive model of interpreting is more viable and instructive on the grounds that it fully illustrates the process of communication in interpreting and interpreters' task of meaning construction. In addition, by further grasping the cognitive model of interpreting, interpreters can develop a better self-awareness and self-monitoring in the pursuit of neutrality.
\end{abstract}

As a unique form of communication, interpreting bridges the gap of understanding between speakers and their audiences with help of interpreters, a linguistic and cultural intermediary (Metzger, 1995; Gile, 2009). The way interpreters establish their roles and fulfill their functions sheds light on the feasibility of different interpreting models, in which the cognitive model benefits all the participants involved in interpreting activities. In the cognitive model, it is an imperative for interpreters to strike a balance between adequate comprehension and proper delivery in the pursuit of neutrality. As a result, an effective communication can be achieved and trust for interpreters themselves can be built (Stewart, Schein \& Cartwright, 1998).

\section{Cognitive Model of Interpreting}

In the cognitive model, there are three steps of rendering the source language to the target language: reception and comprehension; analysis and encoding; expression and evaluation, all of which must be based on a premise that the interpreter understands the language in which the source language messages are presented (Stewart, Schein \& Cartwright, 1998). Interpreting, by its nature, is an active process aimed at communication (Wilcox and Shaffer, 2005). Therefore, interpreters are not passive players; instead, they tend to construct the meaning of information they hear.

According to Wilcox and Shaffer (2005), interpreters deal with three key factors: the nature of language (especially semantics), production and comprehension. Under the framework of those three components, interpreters' social neutrality is inevitably affected, because as a third party in communication, the mere existence of interpreters breaks the one-on-one mode of communication and thus adds uncertainties. However, by adhering to their communicative neutrality, interpreters are aware of the need to do meaning construction as neutrally as possible before delivering their interpreting.

Meaning is not for extraction as in the conduit metaphor that draws an analogy between interpreters and telephones (Solow, 1987); meaning cannot be simply found in the words and then taken out of them. The use of euphemism is a case in point. Vivid examples from the Economist go as follows:

What the British say: "QUITE good.” (with the stress on the "quite”)

What the British mean: "A bit disappointing."

What is understood: "Quite good."

What the British say: "quote GOOD.” (with the stress on the "good”)

What the British mean: "Excellent."

What is understood: "Quite good." 
When spoken with stress on different words, the same sentence can imply different meanings, which cannot be simply inferred from the words only. Therefore, the real meaning is not reflected by the words and literal meaning of words; it is not ready-made for interpreters to extract, but serves as prompts, as cues, for the construction of meaning (Wilcox \& Shaffer, 2005).

Unlike the automatic success of communication suggested by the conduit metaphor, toolmaker paradigm (Reddy, 1979) gives another perspective that points to the necessity of meaning construction. According to the toolmaker paradigm, six people live separately in six spaces with a hub connecting each one of them. When one person makes a tool and is about to share it with the rest five people, he has to teach the tool-making instructions in a written form to the others through the hub. However, the six spaces each features a different living condition, which makes it impossible for the rest five to gain access to exactly the same material of tool used by the first person. As a result, each of the five people makes tools of their own characteristics based on the same instructions. In this sense, the real meaning can never be smoothly and directly acquired from one person to another, because meaning is in the minds of the speaker who produces and understands the expressions (Langacker, 2008) instead of in the words themselves. That is to say, languages and words function as carriers of the form of meaning, not the meaning of meaning. Therefore, it is unlikely for interpreters to extract meaning from speakers' words. What they have to do is to construct meaning by understanding and making an inference based on perceptible evidence (Wilcox \& Shaffer, 2005), which is the core mission of interpreting.

\section{Neutrality and Fidelity}

When the construction of meaning is required, then how can interpreters achieve a neutral role? In Cao Jianxin's (1997) words (in Chinese), interpreters shall stand neutral sans preference, bias and prejudice between two sides who communicate with each other. Given interpreters' job to serve the two sides of talk, they must forget themselves and put them in the position of speakers, trying to think like speakers. Indeed, it is the professional work ethics as well as the self-discipline of interpreters to achieve impartiality and fully grasp the original messages of speakers. This conscious neutral role is highlighted by cognitive model of interpreting.

The toolmaker paradigm demonstrates the fact that communication is sophisticated by nature and its outcomes mixed; chances are that complete communication that achieves every bit of it is implausible. When interpreters are introduced to communication, the ideal is to break down linguistic and cultural barriers so that the intended messages of both sides are successfully delivered and understood. In this process, the best interpreters can do to achieve their neutrality is to achieve fidelity first. Here, fidelity does not refer to the ability to stick to the original grammar or form, but to the true meaning of the original messages (Gile, 2009).

Moreover, the cognitive model holds that the true meaning does not lie in words but in the brain of speakers, who put their thoughts in word production (Stewart, Schein \& Cartwright, 1998). Hearing those words, interpreters shall first construct their meaning before making rendition in another language. It must be noted that construction here has nothing to do with creation. Construction of meaning is built on the original information; all the original words and messages are prompts for construction. The efforts of construction also need to take into consideration the relations between interpreters' subjectivism and fidelity: although the construction of meaning is subjective, the subjective construction must meet the demand of fidelity. Therefore, in an attempt to reach neutrality, the subjective construction of meaning shall be as faithful to the original messages as possible. The better interpreters grasp the prompts of the source language, the more faithful they can be to the true meaning of speakers, and the more neutral they become. To put it more succinctly, construction is aimed at fidelity and fidelity paves way for neutrality.

\section{Social Neutrality and Communicative Neutrality}

Social neutrality is impossible as the two sides who do not speak the same language must be assisted by interpreting (Wilcox \& Shaffer, 2005), which breaks the conventional mode of 
communication; interpreters can do nothing to restore social neutrality. Absolute communicative neutrality is also humanly impossible. But unlike social neutrality, interpreters are capable of enhancing their communicative neutrality when they are fully aware of their mission of meaning construction. In so doing, they do not mistaken themselves as a mouthpiece or machine that does literal output and deviate from the true meaning - when fidelity is lost, neutrality fades away; rather, they know well how they influence the success of communication and therefore tread carefully to monitor their rendition towards neutrality.

\section{Deciding Factors of Neutrality}

Communicative neutrality only comes when interpreters make themselves do it. That requires constant self-monitoring and dealing with factors that can affect neutrality. From the perspective of interpreters, personal differences such as mental and physical conditions, religious beliefs and political leanings play a role (Cao, 1997). On the other hand, interpreters are likely to show partiality for their employers or clients in some cases. Important as those factors are, they are not related to the subject of this paper. The following part will touch upon the two main issues concerning interpreters' role of neutrality when they try to construct the meaning of the source text.

First, the extra-linguistic knowledge of interpreters (Gile, 2009). For example, in the opening remarks of Han Han, a Chinese writer, when he gave speech at Xiamen University, he said (in Chinese): "This is my second visit to the city of Xiamen. The air quality here is good. No wonder you all love to take a walk." Those lines appear to be nothing but polite small talks. However, the true meaning is more than the words themselves suggest. As is observed before, the cognitive model of interpreting sees words as prompts or cues for the recipients. In Han's remarks, the cue words are "take a walk" (the original Chinese is "san bu", literally meaning "take a walk"). What he was referring was an incident of civil disobedience against the local government's plan to build a heavy-polluting p-Xylene chemical plant when Xiamen residents took a walk in forces as a protest. As a result, the plan was dropped, and the expression of "take a walk" thus carried a connotation for people in Xiamen. That is to say, in that context, an interpreter must be able to decipher the pun used by the speaker with the pre-existing knowledge. The more solid such knowledge base is, the more accurate interpreting can be (Gile, 2009). Another example when it comes to euphemism:

What the British say: "Correct me if I'm wrong."

What the British mean: "I know I'm right-please don’t contradict me.”

What is understood: "Tell me what you think."

When an interpreter fails to grasp the cultural-specific usage of euphemism and instead takes words literally, misunderstanding, confusion and embarrassment can easily arise. Seemingly plain words may have intricate and subtle meanings behind. As Ogden and Richards (1923) put it, words actually mean nothing by themselves; they are mere instruments of the true meaning. In order to make the most of the instruments, interpreters shall fully mobilise their extra-linguistic knowledge to offer adequate rendition that is accurate and faithful to the original intended meaning-neutrality is only possible when faithfulness is accomplished.

Second, linguistic information aside, situational information helps interpreters' neutrality as well (Gile, 2009). For instance, following Han Han's opening lines about "take a walk”, there was an outburst of laughter and applause among his audiences. Their response provided clear situational information that "take a walk" meant more than their literal meaning. Therefore, it is fair to conclude that prompts reflected by words and hints reflected by specific situations combined contribute to the neutral role of interpreters. Under the cognitive model of interpreting, linguistic information and prompts is the foremost factor for interpreters to construct meaning. Then with the assistance of situational information, interpreters are able to judge the accuracy and faithfulness of their construction.

To better benefit from both linguistic and extra-linguistic cues, interpreters must have faith in the cognitive model of interpreting. If interpreters mistakenly hold the idea that meaning is readily there and effortlessly within reach for extraction, then they will definitely have trouble decoding the real meaning behind the form of words. As a result, failure of fidelity invariably leads to failure of 
neutrality. However, if interpreters champion the cognitive model and take the responsibility of constructing meaning, they interpret beyond words and at the same time stay mentally alert about the need to be as transparent and neutral as possible. They both know their power and limit the power within the realm of fidelity.

\section{Conclusion}

The cognitive model of interpreting builds a system to demonstrate the legitimacy of interpreters' job to construct the meaning of language. The ability to not to take language at its face value is an active process, in which interpreters deal with messages instead of words only. The key is to recognise interpreting as an operation that requires a balanced relationship between decoding information and meaning construction: this construction lays a foundation for interpreters to develop an awareness of such an activity; the awareness of meaning construction comes under the guiding principle of fidelity, hence a self-imposed neutrality, which is communicative neutrality. Absolute neutrality can only be a theoretical idea, but when neutrality is professionally enforced by interpreters themselves, they make efforts to discipline and monitor themselves in the ongoing activity of interpreting. In other words, by upholding the cognitive model, interpreters are mindful of what limits them and how much leeway they enjoy to make sure that speakers' intended messages are duly sent in another language.

The cognitive model also provides insights into interpreting training. Since communication is doomed to be incomplete and interpreters themselves are different in terms of their backgrounds and skills, the extent to which interpreters can capture and grasp the prompts and hints of linguistic and extra-linguistic differs from one person to another as well. For this reason, the outcomes of the meaning construction of different interpreters must vary. So is there a standard to judge the adequacy of various results of construction? Who is in the right position to judge? Are they trainers, speakers or audiences? These questions remain to be examined in further studies.

\section{References}

[1] Cao Jianxin. (1997). Mental Differences and Physical Factors in Interpreting (in Chinese). Chinese Translators Journal, vol. 1, pp. 25-27.

[2] Gile, Daniel. (2009). Basic Concepts and Models for Interpreter and Translator Training (Revised ed.). Amsterdam/Philadelphia: John Benjamins Publishing Company.

[3] Langacker, Ronald W. (2008). Cognitive Grammar: A Basic Introduction. New York: Oxford University Press, Inc.

[4] Metzger, M. (1995). The Paradox of Neutrality: A Comparison of Interpreters Goals With the Reality of Interactive Discourse. Washington, DC: Georgetown University.

[5] Ogden, C. K. \& Richards, I. A. (1923). The Meaning of Meaning. London: Routledge \& Kegan Paul.

[6] Reddy, Michael J. (1979). The Conduit Metaphor: A Case of Frame Conflict in Our Language About Language. In Ortony, A. (ed.) Metaphor and Thought (pp. 164-201). Philadelphia, USA: Cambridge University Press.

[7] Solow, Sharon Neumann. (2000). Sign Language Interpreting: A Basic Resource Book (Revised ed.). Burtonsville, MD: Linstok Press.

[8] Stewart, David A., Schein, Jerome D., Cartwright, Brenda E. (1998). Sign Lanugage Interpreting: Exploring Its Art And Science. Massachusetts: Allyn \& Bacon.

[9] Euphemistically Speaking: This May Interest You. (2011, May 27). Retrieved from https://www.economist.com/johnson/2011/05/27/this-may-interest-you

[10] Wilcox, Sherman \& Shaffer, Barbara. (2005). Towards a Cognitive Model of Interpreting. Topics in Signed Language Interpreting: Theory and Practice (pp. 27-50). Amsterdam/Philadelphia: John Benjamins Publishing Company. 